\title{
CREATING INTRAPRENEURSHIP AS AN AREA OF CORPORATE ENTREPRENEURSHIP
}

\author{
Urszula Nowacka \\ Jan Długosz University in Częstochowa, Poland \\ Rafal Glębocki \\ Jan Długosz University in Częstochowa, Poland \\ Alina Gil \\ Jan Długosz University in Częstochowa, Poland
}

\begin{abstract}
The article focuses on the characteristics of intrapreneurship as an area of corporate entrepreneurship. Attention was paid to the essence and importance of intrapreneurship in the organization. Then, based on the analysis of activities supporting intrapreneurship undertaken in an international corporation of the banking sector and literature research on this subject, $a$ model was developed to stimulate the creation of intrapreneurship within large organizations. The tools used in the model are divided into tools from the category of people management (soft) and tools related to working methods.
\end{abstract}

Keywords: intrapreneurship, management, organization.

\section{Introduction}

A corporation is a form of enterprise with a defined internal organization with well-defined procedures and relations between its members. The main features of the corporation are: large size and sales, well-organized structures, a large number of employees, state-of-the-art products, advanced technology, and significant capital. In order to grow in a difficult competitive market, a modern corporation should be characterized by innovation, the flexibility of action, and the ability to introduce changes that guarantee success. For this to be possible, various forms of activities supporting entrepreneurship should be introduced, both at the level of organizational structure, creation of procedures, forms of organized action of people in the corporation, as well as at the level of the entity itself. Such a solution seems to be the introduction of corporate entrepreneurship based on company strategy.

Corporate entrepreneurship is understood as "initiatives with entrepreneurial features undertaken within existing, usually large organizations" (Cieślik, 2014, 75). The initiatives were taken and the solutions applied are related to three areas 
(Cieślik, 2014):

- the sphere of strategic management - shaping the so-called entrepreneurial orientation of an organization by, e.g., appointing leaders showing entrepreneurial qualities to essential positions, promoting proactive, innovative actions, accepting risk;

- creating organizational framework, as well as procedures, functional rules that encourage quasi-business projects within the organization, mainly concerning the implementation of new technologies, new products or services, and opening new markets;

- $\quad$ the shaping of intrapreneurship attitudes among employees and changes in the sphere of corporate culture related to the promotion of intraentrepreneurs - leaders of new initiatives and ideas, and rewarding such attitudes.

This study aims to characterize intrapreneurship, its essence, and importance for the development of the enterprise and to present a model containing tools supporting intrapreneurship in large organizations. The analysis of domestic and foreign literature was carried out, as well as interviews with the managers of one of the companies belonging to the international banking sector corporation. The research allows us to determine whether and how large corporate enterprises support or can support intrapreneurship.

\section{The essence and sources of intrapreneurship}

Intrapreneurship can be understood as one of the areas of corporate entrepreneurship.

According to S.A. Zahra, corporate entrepreneurship "is a set of actions aimed at increasing the corporate capacity to innovate, take risks, and take advantage of opportunities" (Zahra, 1993).

J. Cieślik, on the other hand, stresses that corporate entrepreneurship consists in the fact that "within the existing structures of large organizations, conditions are created for the functioning of quasi-independent organizational units, set up on an ad hoc basis to carry out separate tasks and projects” (Cieślik, 2014, p. 76).

Some authors, based on D. Miller, P.H. Friesen, point out that corporate entrepreneurship is an effort to innovate within an already existing, complex corporate structure. Using the definition of entrepreneurship by K.M. Eisenhardt, S.L. Brown, H.M. Neck, they understand corporate entrepreneurship as a set of measures to increase a company's ability to innovate, take risks, and seize opportunities (Piecuch, 2018, p. 71-85).

According to T. Piecuch, corporate entrepreneurship is "a long-term concept that should include a strategic dimension. (...) The inclusion of a strategic 
dimension in the entrepreneurial process enriches the enterprise, contributes to real, long-term, sustainable development, (...) in which strategic thinking and action, competitiveness, social capital, flexibility and mobility, organizational learning, and comprehensive problem-solving are the primary sources of generating values" (Piecuch, 2018, p. 75).

The cited definitions of corporate entrepreneurship allow to define its most important aspects, as shown in Fig. 1.

Intrapreneurship is used to implement the idea of corporate entrepreneurship in order to effectively implement the "entrepreneurial spirit" through employees acting with passion and commitment, who are not afraid to take unconventional and risky actions (Cieślik, 2014).
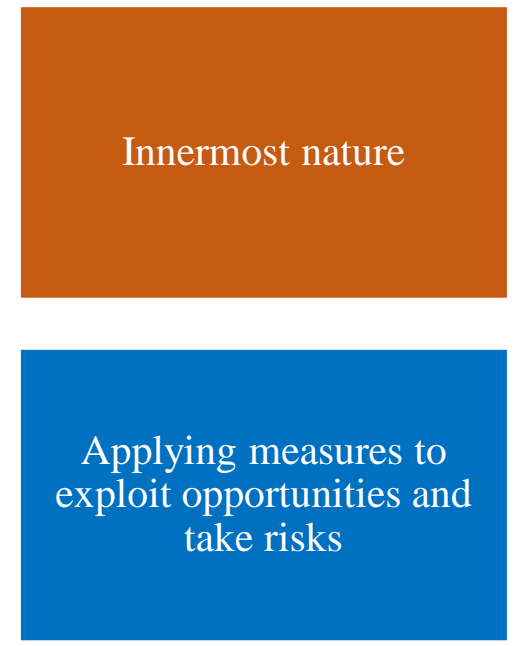

Systemic solutions for the implementation of intrapreneurship within an organization

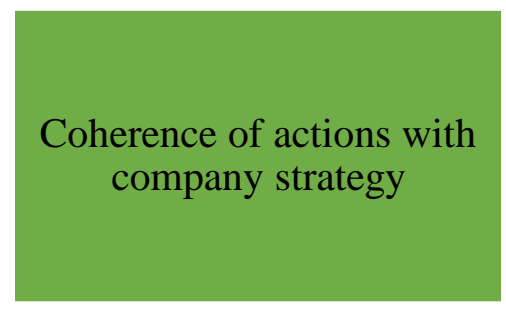

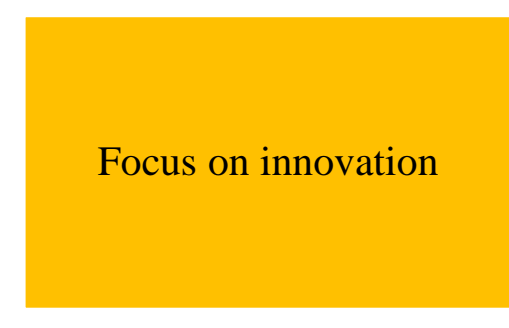

The use of tools to

stimulate and create intrapreneurship attitudes among employees

Figure 1 Characteristic aspects of corporate entrepreneurship (own elaboration)

Intrapreneurship is a process that takes place within existing organizations and leads not only to business ventures but also to other innovative solutions and is a critical element of organizational and economic development (Pinchot, 1985). Intrapreneurship can also be interpreted, following R. Jepperson and J. Mayer, as "a belief in individual autonomy as well as an organizational culture that supports the individual in creating new activities" or, following B. Antonicic and R.D. Hisrich, as a process that "leads not only to new business ventures but also to other activities and orientations, such as the development of new products, services, technologies, administrative techniques and strategies" (LiczmańskaKopcewicz, 2017).

Intrapreneurship is a response to rapidly changing environmental conditions, new customer expectations, and innovative actions of the competition. It allows to fully utilize the potential of employees, their innovative ideas and solutions, and perceive every change as a new opportunity. 
The main activities related to intrapreneurship (which concerns individuals working at all levels of the organization) are: capturing opportunities, taking risks, being proactive, generating new, innovative ideas by creative combining various resources available at a given time.

The intrapreneurship potential is built through the creation of structures and organizational cultures that facilitate trust and cooperation (LiczmańskaKopcewicz, 2017), but also through a democratic and participatory steering system, creating a climate for change, an efficient system of communication and information flow.

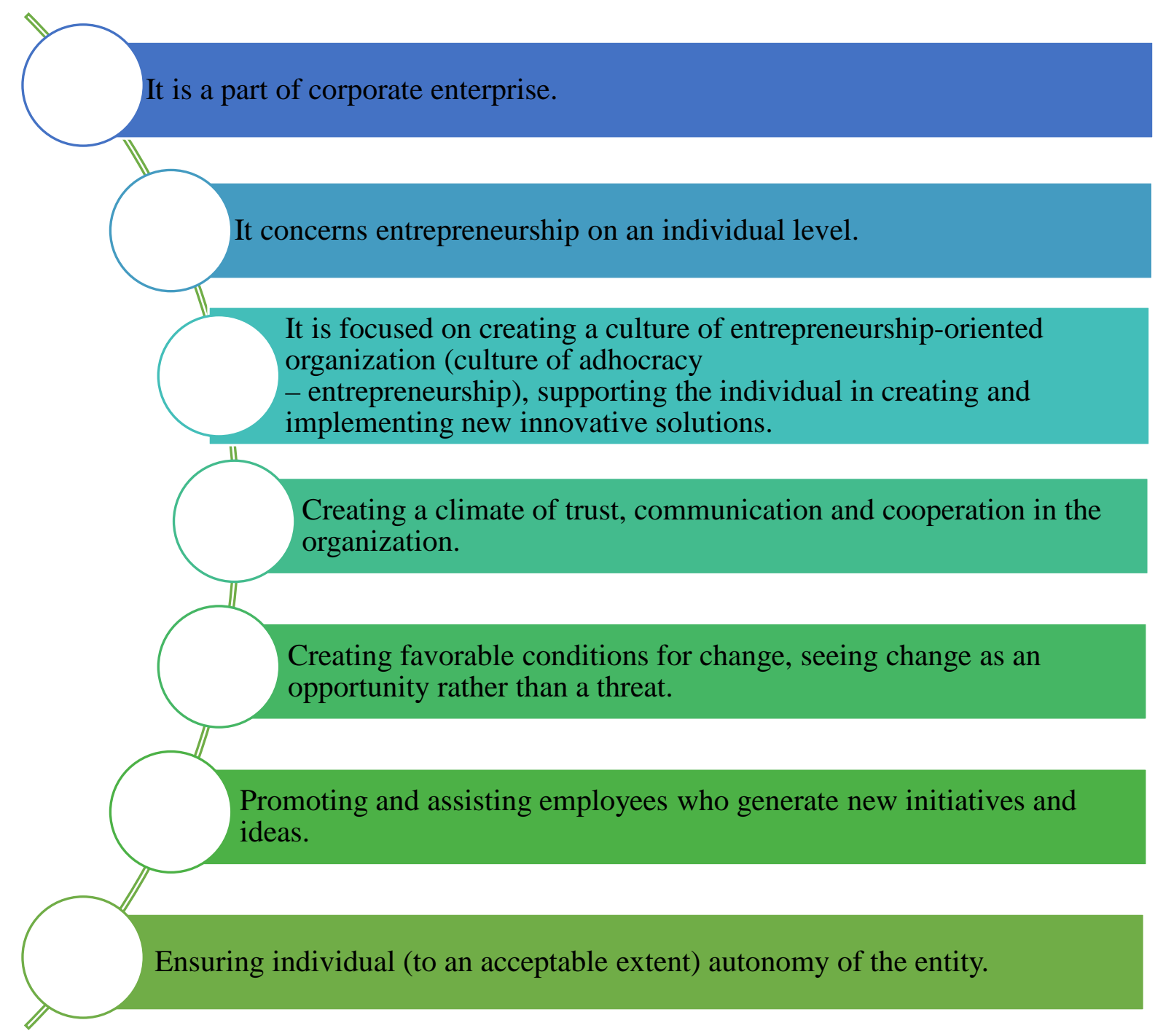

Figure 2 Characteristic aspects of intrapreneurship (own elaboration)

The concept of intrapreneurship is often identified in the literature as corporate entrepreneurship, but it is a narrower concept referring only to the creation of conditions and stimulation of entrepreneurial attitudes at the individual 
level, which means that the central figure of the intra-entrepreneurial process is the intra-entrepreneur. An intra-entrepreneur is a proactive person employed in a large enterprise, characterized by the ability to use and develop their entrepreneurial qualities, distinguished by specific patterns of behavior, including creativity, creative thinking, and the ability to take challenges and initiate change. The most important aspects of intrapreneurship are presented in Fig. 2:

To sum up, the intrapreneurship in the conditions of a challenging, competitive market is a critical success factor, leads to the effective generation and implementation of new innovative solutions, and, at the same time, influences the individual development of employees who are satisfied with their professional work.

\section{Methodology}

The research included studies of domestic and foreign literature and interviews with the managers of all levels of the organizational hierarchy in an enterprise belonging to an international banking sector corporation operating in Poland. The research aimed to determine whether and how large corporate enterprises support or how they can support intrapreneurship, and to provide information to build a model that presents tools to stimulate intrapreneurship in large organizations.

The research was conducted in April-October 2019. The average duration of the interview was 1-1.5 hours. The interview was conducted with 19 managers (including 10 front line managers, 6 - middle level managers and 3 - top-level).

The purpose of an interview as a method of qualitative research is exploration, which consists in collecting and evaluating relevant data on both the existing theory and empirical reality in order to use the results of research to develop the theory. The research allowed us to identify methods and ways of shaping intrapreneurship and to generate and present proposals to use existing and new tools/categories to create intrapreneurship in large organizations.

The choice of the in-depth individual interview as a research method was not accidental, because it was not possible to obtain detailed opinions and information, to establish facts about the actual activities taking place in the company concerning intrapreneurship through other research techniques such as a questionnaire. Moreover, in the case of respondents with difficult access (persons with a significant professional position, e.g., middle and senior managers), the time and place of the interview had to be adjusted to the preferences of individual respondents (which would not be accessible in the case of a group interview).

Data acquisition using a direct interview was carefully prepared; a list of questions was established, which constituted the main content of the interview. 
The questions concerned, among others, the following: Does the company, in its action strategy in a formalized way, have specific tools/methods stimulating intrapreneurship?; What are these tools?; Which of the methods/tools are most frequently used in the company?; Which of the tools are rated highest when it comes to stimulating intrapreneurial attitudes among employees?; How does the company motivate employees to be intrapreneurial?; What are the most considerable difficulties in the process of implementing these tools/methods?; Do employees' individual social and professional competences influence the choice of techniques/methods for creating entrepreneurship, if so, which ones?; How does the company manage resistance to change?

Due to the limitations of the article's volume, and the extensive material collected as a result of the research, the article focuses only on generating techniques and methods influencing the creation of intrapreneurship in a large organization. The information collected as a result of the research will be used to prepare further articles.

The analysis of the conducted interviews shows, among others, that the surveyed company has implemented and implements a formal system of supporting intrapreneurship behavior, including the following tools and working methods: 1:1 meetings, communication through results, development of crossarea competences, safety culture, CI model, ITIL Guiding Principles or "coding festival”.

\section{Analysis of research results}

The analysis of research results allowed us to build a model presenting tools that stimulate intrapreneurship in large organizations.

Ways of dealing with employees, especially the methods influencing the formation of certain attitudes, behaviors, motivation to change the way of work used by managers include both soft and hard management techniques. It is worth using various techniques; therefore, the model presented below includes aspects derived from both soft and hard management techniques.

The essential attribute of soft management is treating people as the most important capital of the organization. It boils down to creating an appropriate atmosphere at work, so that it is as friendly as possible, even family-like, i.e., taking care of the employee's needs and his/her well-being. An employee is an entity, co-creator, the most crucial link in the organization, and his or her knowledge and skills are the source of competitive advantage and value of the organization.

Hard management methods consist in creating a feeling in the employee that he or she has to fulfill the tasks and point out possible ways of achieving them. Then the employer becomes instead a kind of a person who controls and enforces 
the completion of tasks, etc. In the article, some formalized methods of work have been chosen, understood as conduct based on research principles, which aims at solving organizational problems and, at the same time, has a significant impact on stimulating intrapreneurship development in large corporate enterprises. Moreover, using only soft techniques is not the right solution because there are employees who simply need to be shown what their duties are when they should be fulfilled, what methods they have at their disposal, etc., which is also confirmed by analyses of conducted interviews.

The rational use of different aspects of soft and hard management depends on the situation, personal and leadership skills of the manager. Undoubtedly, a well-thought-out combination of these two different approaches gives the manager great flexibility and more excellent opportunities to influence individual employees in the company in order to create intrapreneurial attitudes.

The tools used in the model were divided into tools from the category of human management (soft) and tools related to working methods (Fig. 3).

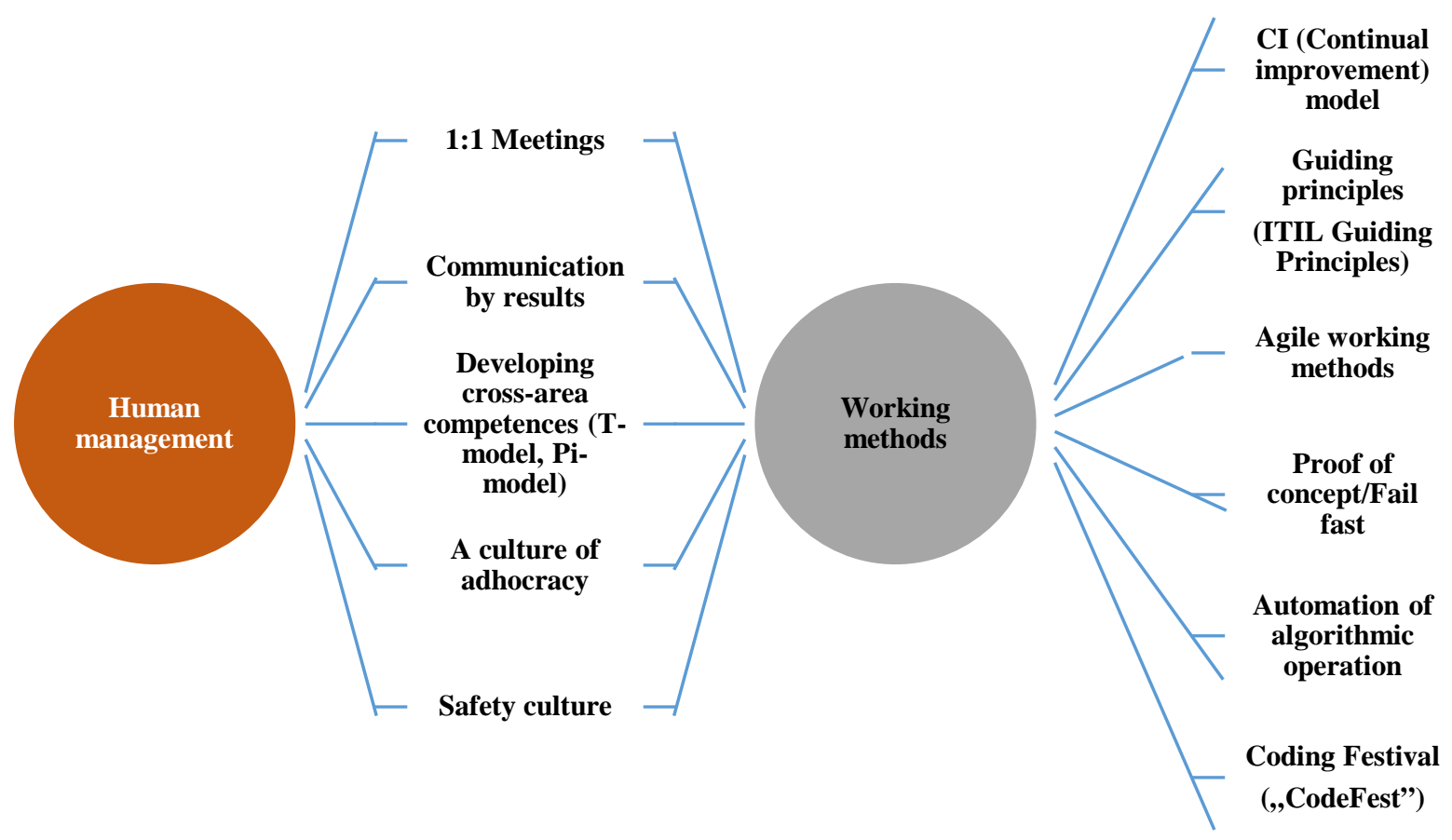

Figure 3 Model presenting tools creating intrapreneurship in large organizations (own elaboration)

Tools from the human management category - "soft":

a. 1:1/face-to-face meetings - allow the employee to share their problems and ideas with their immediate supervisor. The manager should support the employee by eliminating barriers to achieving objectives and 
support development initiatives. Such a tool promotes and appreciates employees who generate new initiatives and ideas and shows the way and helps in the implementation of new projects (Belker, Cormick, \& Topchik, 2018).

b. Communication by results - one of the good practices is to set goals for employees in the form of results to be achieved, not in the form of work to be done. This tool leaves room for innovation and creativity, and thus supports the development of intrapreneurship (ITIL 4, 2020).

c. Developing cross-area competences (T-model, Pi-model) - broad competences of employees lead to a better understanding of the value stream and developing solutions addressing the needs not only of a single team but of the entire organization.

As recently as a dozen or so years ago, the most popular knowledge models were horizontal (broad knowledge on various subjects, but not indepth) or vertical (area-based, in-depth knowledge on a given subject) Fig. 4a.

Currently, companies are looking for people with broad general knowledge specialized in one (T-model) - Fig.4b or several (Pi-model) - Fig.4c fields (ITIL 4, 2020).

\section{a) Horizontal knowledge}

c) b)
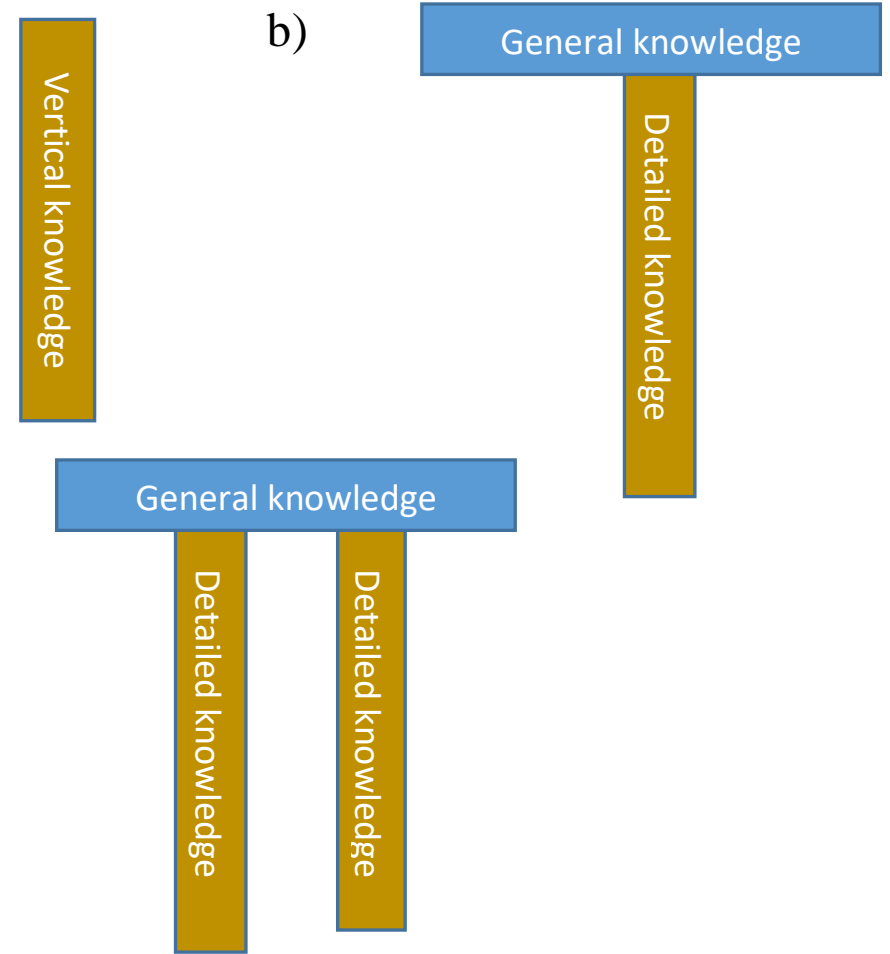

Figure 4 Developing cross-area competences: a) horizontal and vertical model, b) T-model, c) Pi-model (own elaboration) 
d. A culture of adhocracy - is associated with the existence of a dynamic and creative working environment. Employees take risks, and leaders introduce innovative solutions. Experiments and innovations allow for development. The success is in running new products and services. Freedom and individual initiative are appreciated values. It is a culture that characterizes innovative organizations, which are focused on fluidity and constant change. It is often used in companies that are focused on continuous development, dynamics, and adaptation to changing reality. In the culture of adhocracy, power is exercised by those who know the issue best: often, depending on the project, a completely different team can be formed, with other leaders and managers. Companies with a predominantly adhocratic culture stand out from the competition with their high adaptability and proinnovative and non-stereotypical way of operating (Świtała \& Mościcki, 2016; Olszewska, 2014).

e. Safety culture - current organizations are continually trying to improve their services. It puts pressure on employees and often results in professional burnout. Promoting a culture where making a mistake is the ordinary course of action allows the employee to do the job with less stress and, therefore, usually a better one. It helps to promote a culture of addressing the systemic cause of errors, not looking for guilty ones. With such a culture, employees are willing to take risks and try new solutions, increasing the organizational maturity of the company (Crutchfield \& Roughton, 2013). It allows the company to create a climate based on trust, effective communication, and cooperation and creates favorable conditions for change and perception of change as an opportunity rather than a threat.

Working methods:

a. CI (Continual improvement) model - the model described in the ITIL Practitioner (ITIL ${ }^{\circledR}$, 2011) publication is showing how to improve processes, products, and services continuously. Continuous improvement should take place in all areas and at every level of the organization, from strategic to operational ones. In the company analyzed in the research, in order to maximize the effectiveness of services, every person who contributes to service delivery should be aware of the need for continuous improvement and continuously look for opportunities to improve working methods, processes, products, and services.

The ITIL Continual Improvement model (Fig. 5) is based on the Deming Cycle (PDCA) and can be used as a high-level guide to managing improvement initiatives. Using the model increases the likelihood of 
successful improvement initiatives, puts the customer's value at the heart of the initiatives, and at the same time, ensures that improvement activities are in line with the organization's vision.

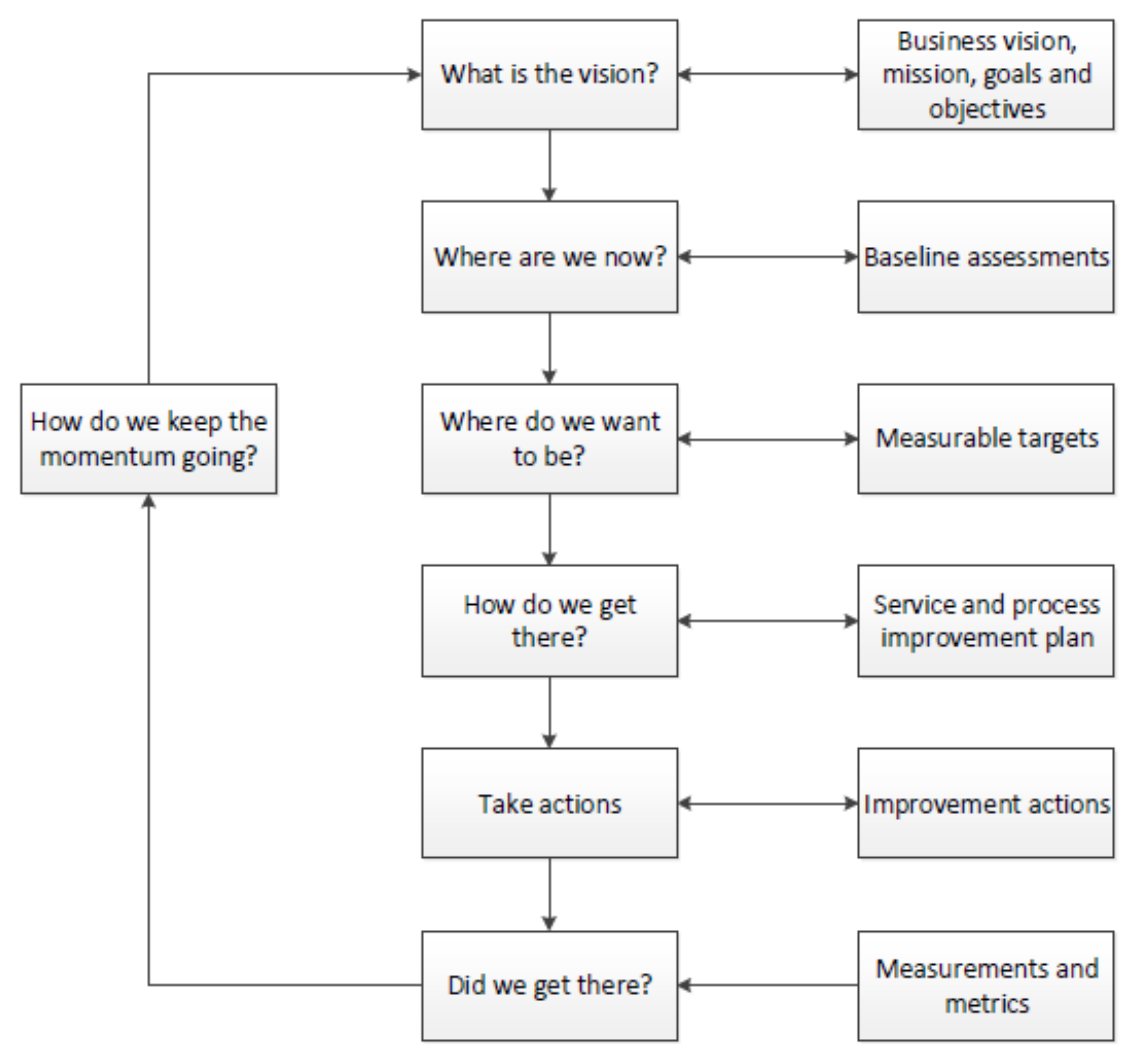

Figure 5 ITIL CI (Continual improvement) model (ITIL $®, 2011)$

The model consists of seven steps:

1) What is the vision? - Agree on a vision for a streamlining initiative by understanding the objectives and needs of the business. The vision should be consistent with the organization's strategy.

2) Where are we now? - assess the current situation measurably. It will help to set the objectives of the initiative at a later stage and assess the success or failure of the initiative.

3) Where do we want to be? - set measurable targets for the vision set out in the first point. The objectives should be consistent with the concept of formulating SMART objectives - the objective should be specific, measurable, achievable, relevant, and on time.

4) How do we get there? - create an accurate plan to reach the goals set out in point three.

5) Take action - follow the plan created in point four. 
6) Did we get there? - assess the measurable effects of the initiative and compare the effects with the baseline (the second point) and the objectives to be achieved by the initiative (the third point).

7) What are we going to do to keep it going? - ensure that the results achieved by the initiative will be sustained (that the organization will not go backward), draw lessons from the improvement initiative, and ensure continuity in improvement - move on to forming a vision for the next improvement initiative.

The model strongly supports activities related to intrapreneurship, ensuring that individual improvement actions are tailored to the objectives of the entire organization, setting specific objectives to be achieved, measuring the level of achievement of these objectives, and ensuring that the organization continues to improve.

b. The ITIL Guiding Principles - a set of principles that an organization should consider in all situations. The set of principles was first published in the ITIL Practitioner publication and improved in the next version of ITIL Good Practice - ITIL 4 (ITIL 4, 2019).

The Guiding principle constitutes recommendations that guide the organization under all circumstances, regardless of changes in the organization's objectives, strategy, type of work, or management structure. The Guiding principles are universal and durable.

ITIL 4 proposed seven primary principles:

1) Focus on values - everything an organization does must be mapped (directly or indirectly) to the value for its stakeholders. Every employee should know how their work translates into the value the organization wants to achieve.

2) Start where you are - do not start from scratch and do not build it all over again, without evaluating what works well in the current approach and can be used in a new solution.

3) Progress iteratively with feedback - do not try to do everything right away. Primarily large initiatives should be carried out iteratively. By dividing the work into smaller parts, it is easier to manage the initiative, and we can get feedback faster and use it for further iterations.

4) Collaborate and promote visibility - storm the silos between teams and promote the visibility of work.

5) Think and work holistically - results, both to internal and external customers, are delivered through effective management and dynamic integration of information, technology, organizations, people, practices, and partners. All elements should be coordinated to provide a defined value. 
6) Keep it simple and practical - if a process, service, the action does not provide any value - eliminate it. Always use the smallest number of steps to reach the goal.

7) Optimize and automate - optimize and automate everything that makes sense. Use people to do creative work. First, optimize, then automate. Automated chaos is still chaos.

The primary principles ensure that intrapreneurship activities always provide value for the organization and help the individual to maintain the framework within which they should operate.

c. Agile working methods - Agile (e.g., Scrum, Kanban) - Agile working methods allow for faster delivery of business value and faster feedback to the originator (intra-entrepreneur). It makes it easier to adapt new or improved products and services to the ever-changing needs of the business.

In the case of intrapreneurship, it is vital to quickly verify whether ideas that improve the organization add real value for stakeholders. Agile methods promote large dividing initiatives into smaller parts and performing the work iteratively, with compression back after each iteration (Kniberg \& Skarin, 2010, Layton, 2012).

d. Proof of concept/Fails fast - creating mechanisms in which employees can test their ideas (Proof of concept) and creating the culture in which quick information that we are going in the wrong direction is the key. An essential element is the promotion of "quick failures." If we are to fail, it is better to do it at the earliest possible stage of the project than to continue a project that will not deliver business value (fail fast) (Babineaux \& Krumboltz, 2013). Such mechanisms ensure the individual autonomy of the individual and reduce the risk for both the innovative employee (intra-entrepreneur) and the whole organization.

e. Algorithmic work automation - good practice is to automate as much as possible the algorithmic work (process, repetitive) in order to free up human resources for more creative work (heuristic work). Instead of performing repetitive tasks, employees may focus on improving the organization and developing intrapreneurship in the organization (ITIL 4, 2019).

f. The Coding Festival ("CodeFest") - in many organizations including the surveyed corporate enterprise - devotes time for employees to a common (IT and business) definition of the problem and to work out the best solution (not necessarily in the area in which the employee works). It builds an intrapreneurship culture and helps focus on initiatives that are valuable to the organization. An important 
element here is the recognition of employees for initiatives to improve organizations.

\section{Conclusions}

Corporate entrepreneurship, including intrapreneurship, are essential aspects of modern corporations that want to take a leading position on the market and sometimes also a condition for their survival. The larger the enterprise, the more difficult it is to provide an environment conducive to the development of intrapreneurship, if only because of the higher number of procedures, formal, bureaucratic rules to be followed, which often make it difficult or even impossible to introduce changes and reduce flexibility. Intrapreneurship is a prerequisite for increasing a corporation's ability to innovate.

The presented model is only a proposal containing selected tools and working methods, both described in the literature and results from practical solutions used in corporate enterprises to stimulate intrapreneurship.

Through the use of the tools and working methods listed in the model, it becomes possible to put in place an internal "entrepreneurial spirit" within hierarchical, formalized structures. It promotes proactive, innovative, and risks accepting activities and, at the same time, strengthens employees' activity and ensures that their commitment is appreciated. As a result, it also leads to the perception of such corporations as attractive employers and makes it possible to acquire the most valuable employees who derive satisfaction from professional work (Cieślik, 2014).

Although the issues of corporate and intra-company entrepreneurship have been discussed in the literature for a long time, the changes caused by the processes of globalization and the development of new concepts in the sphere of management still emerge as new opportunities and solutions that serve one purpose - to succeed in a demanding, competitive market.

The considerations presented in the publication do not fully cover the subject matter, they are only a proposal, and a starting point for further research carried out on the examples of large organizations which, using these or other mutually reinforcing and complementary tools, create an environment of intrapreneurship, without which it is impossible to implement innovations that are the basis for the development of corporate enterprises.

\section{Summary}

To sum up, it should be stated that intrapreneurship rarely occurs naturally in enterprises and usually requires actions that will stimulate and develop them. Activities leading to the creation of intrapreneurship attitudes are most often focused on one or several selected aspects, e.g., practical and straightforward promoting the ideas of employees, or creating a climate based 
Nowacka et al., 2020. Creating Intrapreneurship as an Area of Corporate Entrepreneurship

on trust, cooperation, creating favorable conditions for change, or ensuring autonomy and freedom of action of an individual. The tools and working methods proposed in the article are complementary and permeate each other, and it depends on the company and its strategy to select them and implement a specific, coherent system supporting intrapreneurship.

\section{References}

Babineaux, R., \& Krumboltz, J. (2013). Fail Fast, Fail Often: How Losing Can Help You Win. Tarcher Perigee.

Belker, L.B., Cormick, J.Mc., \& Topchik, G.S. (2018). The First-Time Manager Hardcover. AMACOM, 7th ed.

Cieślik, J. (2014). Przedsiębiorczość Polityka Rozwój (Etrepreneurship Polotics Developement). Warsaw: Wydawnictwo Akademickie SEDNO.

Crutchfield, N., \& Roughton, J. (2013). Safety Culture: An Innovative Leadership Approach. Butterworth-Heinemann, 1st ed.

ITIL 4 Managing Professional: Create, Deliver and Support. (2019). AXELOS Global Best Practice, ITIL Official Publisher.

ITIL 4 Managing Professional: Create, Deliver and Support. (2020). AXELOS Global Best Practice, ITIL Official Publisher.

ITIL ${ }^{\circledR}$ Continual Service Improvement. (2011). AXELOS Global Best Practice, ITIL Official Publisher.

ITIL ${ }^{\circledR}$ Foundation, ITIL 4th ed. (2019). AXELOS Global Best Practice, ITIL Official Publisher.

Kniberg, H., \& Skarin, M. (2010). Kanban and Scrum: Making the Most of Both. Enterprise Software Development Series.

Layton, M.C. (2012). Agile Project Management for Dummies. For Dummies.

Liczmańska-Kopcewicz, K. (2017). Intra-przedsiębiorczość jako źródło innowacyjności przedsiębiorstw w sektorze FMCG (Intrapreneurship as a source of innovation in enterprises in the FMCG sector). Management Forum, 5(4), 1-7.

Olszewska, M. (2014). Cechy kultury organizacyjnej warunkujące podejmowanie działań pozabiznesowych (Features of organizational culture conditioning the taking of nonbusiness activities). Ethics in Economic Life, 17(3), 75-90.

Piecuch, T. (2018). Strategiczne aspekty przedsiębiorczości korporacyjnej (Strategic aspects of corporate entrepreneurship). Organizacja i Kierowanie (Organization and management), 4(183), 71-85.

Pinchot, G. (1985). Intrapreneuring. New York: Harper \& Row.

Świtała, M., \& Mościcki, M. (2016). Identyfikacja profilu kultury organizacyjnej usługodawcy logistycznego z wykorzystaniem modelu wartości konkurujących (Identification of the organizational culture profile of a logistics service provider using the competitive value model). Studia Ekonomiczne. Zeszyty Naukowe Uniwersytetu Ekonomicznego w Katowicach (Economic Studies. Scientific Journals University of Economics in Katowice), 306, 20-33.

Zahra, S.A. (1993). Environment, corporate entrepreneurship, and financial performance: A taxonomic approach. Journal of Business Venturing, 8, 319-340. 